\title{
Light Regime Characterization in an Airlift Photobioreactor for Production of Microalgae with High Starch Content
}

\author{
Bruno D. Fernandes • Giuliano M. Dragone • \\ José A. Teixeira • António A. Vicente
}

Received: 22 May 2009 / Accepted: 15 September 2009 /

Published online: 21 February 2010

(C) Springer Science+Business Media, LLC 2009

\begin{abstract}
The slow development of microalgal biotechnology is due to the failure in the design of large-scale photobioreactors (PBRs) where light energy is efficiently utilized. In this work, both the quality and the amount of light reaching a given point of the PBR were determined and correlated with cell density, light path length, and PBR geometry. This was made for two different geometries of the downcomer of an airlift PBR using optical fiber technology that allows to obtain information about quantitative and qualitative aspects of light patterns. This is important since the ability of microalgae to use the energy of photons is different, depending on the wavelength of the radiation. The results show that the circular geometry allows a more efficient light penetration, especially in the locations with a higher radial coordinate $(r)$ when compared to the plane geometry; these observations were confirmed by the occurrence of a higher fraction of illuminated volume of the PBR for this geometry. An equation is proposed to correlate the relative light intensity with the penetration distance for both geometries and different microalgae cell concentrations. It was shown that the attenuation of light intensity is dependent on its wavelength, cell concentration, geometry of PBR, and the penetration distance of light.
\end{abstract}

Keywords Microalgae - Optical fiber - Incident light spectrum $\cdot$ Light absorption · Airlift photobioreactor

\section{Introduction}

Biological $\mathrm{CO}_{2}$ fixation and energy production are potential measures expected to mitigate the increase of atmospheric $\mathrm{CO}_{2}$ concentration and to minimize future energy crises. Alternative approaches for biofuel generation have identified aquatic microalgae as fastgrowing species. Some microalgae exhibit carbon fixation rates and solar conversion efficiencies, an order of magnitude greater than those of typical land-based plants [1].

B. D. Fernandes • G. M. Dragone $•$ J. A. Teixeira • A. A. Vicente $(\bowtie)$

IBB - Institute for Biotechnology and Bioengineering, Centre of Biological Engineering,

University of Minho, Campus de Gualtar, 4710057 Braga, Portugal

e-mail: avicente@deb.uminho.pt 
Microalgae have a greater capacity for photosynthesis than higher plants, which raises the possibility that they could effectively utilize the $\mathrm{CO}_{2}$ in stack gases from thermal power plants to synthesize a variety of valuable substances like starch or oil [2, 3].

Another important fact is that the microalgal biomass composition can be influenced via different cultivation conditions in order to achieve better outputs, e.g., of reserve materials (starch and oil). Illumination is the most important factor influencing biomass composition, growth rate, and product formation. Microalgae need carbon dioxide as the carbon source and light within the photosynthetically active radiation (PAR) to obtain energy by photosynthesis. The wavelength of the PAR ranges from 400 to $700 \mathrm{~nm}$, which is equal to visible light [4].

In spite of the huge interest in biofuel production from microalgae, the economic aspects of the process are still to be satisfactorily solved. Therefore, the most important engineering aim in this area is the development of a process that provides biomass, which is rich in chemical energy at the lowest cost. Assuming that the best algal species for the process is identified and selected, the next quest remaining is an optimal design of the bioreactor. Such optimization requires a deep knowledge of the system [5]. In fact, the slow development of microalgal biotechnology stems from the failure in the design of large-scale photobioreactors where light energy is efficiently utilized. Due to the light gradient inside the reactor and depending on the mixing properties, algae are subjected to light/dark cycles where the light period is characterized by a light gradient. These light/dark cycles will determine productivity and biomass yield on light energy.

Productivity is determined by the growth rate which, for fixed fluid dynamics and temperature, is a function of the light profile within the reactor and the light regime to which the cells are subject to. In dense microalgal cultures, light penetration is impeded by self-shading and light absorption [6-8]. These effects affect the radiation profile inside the culture [9].

Airlift bioreactors have been indicated as attractive alternatives for cell cultivation [1]. This might be due to several main advantages such as good mixing, well-defined fluid flow patterns, relatively high gas-liquid mass transfer rate, and low capital and operating costs. If the volumes enclosed by annulus and draft tube can be regarded as illuminated and dark regions, respectively, this flow pattern gives defined light/dark cycles for photosynthetic cells culture. However, because of the nature of the decay in illuminance mentioned above, the description of the annulus as an "illuminated region" is in most cases an oversimplification. Local differences in photon flux density (PFD) will appear as one departs from the illuminated surface. Hence, the cell trajectories in the light zone, i.e., the liquid flow patterns in the downcomer, are required in order to describe properly the light story of a photosynthetic cell [10].

In order to develop a mathematical model predicting microalgal photosynthesis or growth in a photobioreactor (PBR), it is a prerequisite to quantitatively and qualitatively describe light penetration through the microalgal suspension [10]. To relate the light supply with the culture growth, light attenuation in the biological turbid medium must be accurately described. This determination is not trivial and is highly correlated to the PBR geometry $[11,12]$.

The utilization of optical fiber technology allows obtaining information about quantitative (photosynthetic photon flux density) and qualitative (spectral intensity distribution) aspects of light patterns, which is important since the ability of microalgae to use the energy of photons is different, depending on the wavelength of the radiation. This technology was used in the present work aiming to determine both the quality and the amount of light at different points of two alternative geometries of the downcomer of an 
airlift PBR as a function of the microalgae cell concentration and of the light penetration distance. The final goal is to characterize the light regime of the downcomer of the airlift PBR in view of its future utilization for the production of microalgae with high starch content for bioethanol production.

\section{Materials and Methods}

\section{Microorganism}

Strain P12 of the single-celled fresh water alga Chlorella vulgaris was selected because of its capacity to accumulate starch up to $50 \%$ of dry weight, under the appropriate cultivation conditions [13]. It has a high specific growth rate (about $0.25 \mathrm{~h}^{-1}$ under optimal conditions), and it is able to grow under a high concentration of $\mathrm{CO}_{2}$, which enables to supply the cultures directly with flue gas containing $10-13 \%(v / v)$ of $\mathrm{CO}_{2}$ without dilution. The strain is deposited in the Culture Collection of Algal Laboratory, Institute of Botany, Academy of Sciences of the Czech Republic, Centre of Phycology, Dukelska 135, Trebon CZ-379 82.

\section{Growth Medium}

The microalgae were grown in 1-1 Schott flasks with $400 \mathrm{ml}$ of medium, using the composition described by [13]. The original growth medium based on the elementary composition of algal biomass had the following initial composition $\left(\mathrm{mg} \mathrm{l}^{-1}\right): 1,100$ $\left(\mathrm{NH}_{2}\right)_{2} \mathrm{CO}, 237 \mathrm{KH}_{2} \mathrm{PO}_{4}, 204 \mathrm{MgSO}_{4} .7 \mathrm{H}_{2} \mathrm{O}, 40 \mathrm{C}_{10} \mathrm{H}_{12} \mathrm{O}_{8} \mathrm{~N}_{2} \mathrm{NaFe}, 88 \mathrm{CaCl}_{2}, 0.83 \mathrm{H}_{3} \mathrm{BO}_{3}$, $0.95 \mathrm{CuSO}_{4} .5 \mathrm{H}_{2} \mathrm{O}, 3.3 \mathrm{MnCl}_{2} .4 \mathrm{H}_{2} \mathrm{O}, 0.17\left(\mathrm{NH}_{4}\right)_{6} \mathrm{Mo}_{7} \mathrm{O}_{24} .4 \mathrm{H}_{2} \mathrm{O}, 2.7 \mathrm{ZnSO}_{4} .7 \mathrm{H}_{2} \mathrm{O}, 0.6$ $\mathrm{CoSO}_{4} \cdot 7 \mathrm{H}_{2} \mathrm{O}, 0.014\left(\mathrm{NH}_{4}\right) \mathrm{VO}_{3}$ in distilled water; the initial $\mathrm{pH}$ was adjusted to 7.0 by $0.1 \mathrm{M} \mathrm{NaOH}$.

\section{Photobioreactor}

The culture was transferred into a set of acrylic PBRs (Fig. 1) that represent the cross section of two different geometries of the downcomer of an airlift PBR that is being developed. The draft tube was not fitted in the PBRs during the experiments.
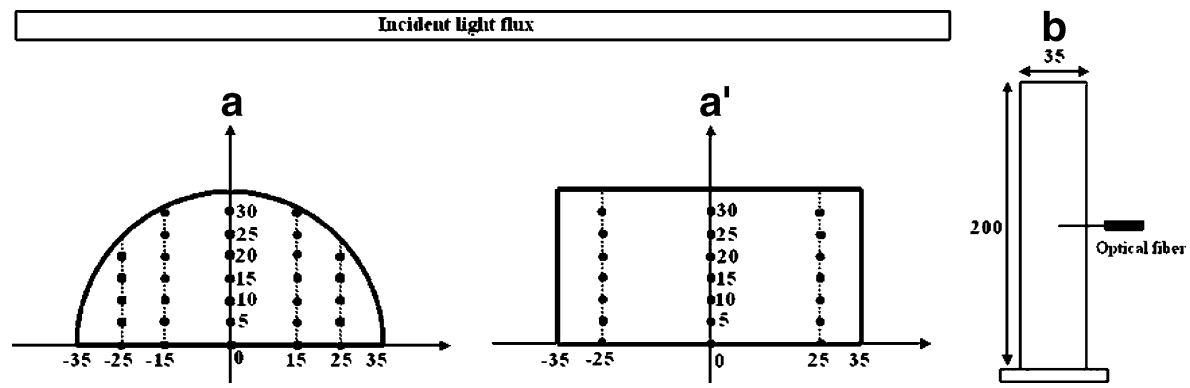

Fig. 1 Top view of an airlift downcomer section a $P B R_{C}, \mathbf{a}^{\prime} P B R_{P}$, and b lateral view of an airlift downcomer section with an optical fiber attached; the position of the measuring points is indicated by circles. All dimensions are in $\mathrm{mm}$ 
The PBRs were illuminated by a set of four fluorescent lamps (Sylvania Standard F18W) placed horizontally and uniformly distributed around the reactor walls at ca. $15 \mathrm{~cm}$ from its surface with an incident light intensity or photosynthetic photon flux density (PPFD) of $70 \mu \mathrm{E} \mathrm{m}^{-2} \mathrm{~s}^{-1}$. The PPFD was determined, in the absence of the microalgal culture, behind the front surface of the reactor, by averaging the values of light intensities measured with a LI-COR Quantum/Radiometer/Photometer Model LI-250 Light Meter (San Diego, CA, USA). This value was taken as the reference value when calculating the relative light intensity (see below) [14].

The quantitative and qualitative characterization of light regime was performed using a fiber optic spectrometer AvaSpec-2048-4-DT (2048 pixel, 200-1,100 nm) coupled with a standard transmission probe, model T300-RT-VIS/NIR, controlled by AvaSoft 6.0 software. Data were acquired between 200 and $1,100 \mathrm{~nm}$, but only the range between 400 and $700 \mathrm{~nm}$ (PAR) was used for calculations, for two reactor configurations (circular and plane) at 14 cell concentrations (ranging from 0.18 to $2.29 \mathrm{~kg} \mathrm{~m}^{-3}$ ), three different radial positions for the circular geometry bioreactor, two different radial positions for the plane geometry bioreactor, and six or seven light penetration distances, depending on the probe radial position and the reactor configuration.

The quantification of the light penetrating in the algal culture was made through the calculation of the relative light intensity (RLI), which is expressed as the ratio of the light intensity (LI) measured at a given point and the reference light intensity $\left(\mathrm{LI}_{\mathrm{R}}=70 \mu \mathrm{E} \mathrm{m} \mathrm{m}^{-2} \mathrm{~s}^{-1}\right)$, measured at the inside wall of the vessel filled with medium in the absence of algae (Eq. 1).

$$
\mathrm{RLI}=\frac{\mathrm{LI}}{\mathrm{LI}_{\mathrm{R}}} \times 100
$$

The concentration of suspended algal biomass was determined both by optical density measurement $(700 \mathrm{~nm})$ and oven drying at $60^{\circ} \mathrm{C}$ for $24 \mathrm{~h}$ [15]. All measurements were made in triplicate, and in all experiments, the standard deviation was always below $5 \%$.

\section{Results and Discussion}

\section{Overall Characterization of Light Intensity}

Light intensity distribution within the culture vessel (Fig. 2) shows cross-sectional distributions of RLI within the two different geometries filled with the algal suspension at different cell concentrations $\left(0.95\right.$ and $\left.2.67 \mathrm{~kg} \mathrm{~m}^{-3}\right)$.

It can be observed in Fig. 2 that for both evaluated cell densities, the irradiance within the two different geometries varied as a function of position. Cells nearer the light-receiving surface experienced a higher irradiance than cells elsewhere in the vessel. Cells closer to the light source shade those further away; hence, productivity varies with position and time [16, 17]. Figure 2 also shows that for both PBR geometries, the relative light intensity at the same distance from the light-receiving surface decreased as the cell density was increased. Such behavior was also observed for cell densities lower than $0.95 \mathrm{~kg} \mathrm{~m}^{-3}$ (Fig. 3).

Figure $2 b, b^{\prime}$ clearly shows that the plane geometry leads to a more uniform light distribution (this is more evident for higher cell concentrations-Fig. 2b'); the circular geometry allows a more efficient light penetration, especially in the locations with a higher radial coordinate $(r)$.

For low cell concentrations (Fig. 2a, b), the differences between the geometries are negligible, possibly due to the low intensity of the scattering phenomena; in this case, those 

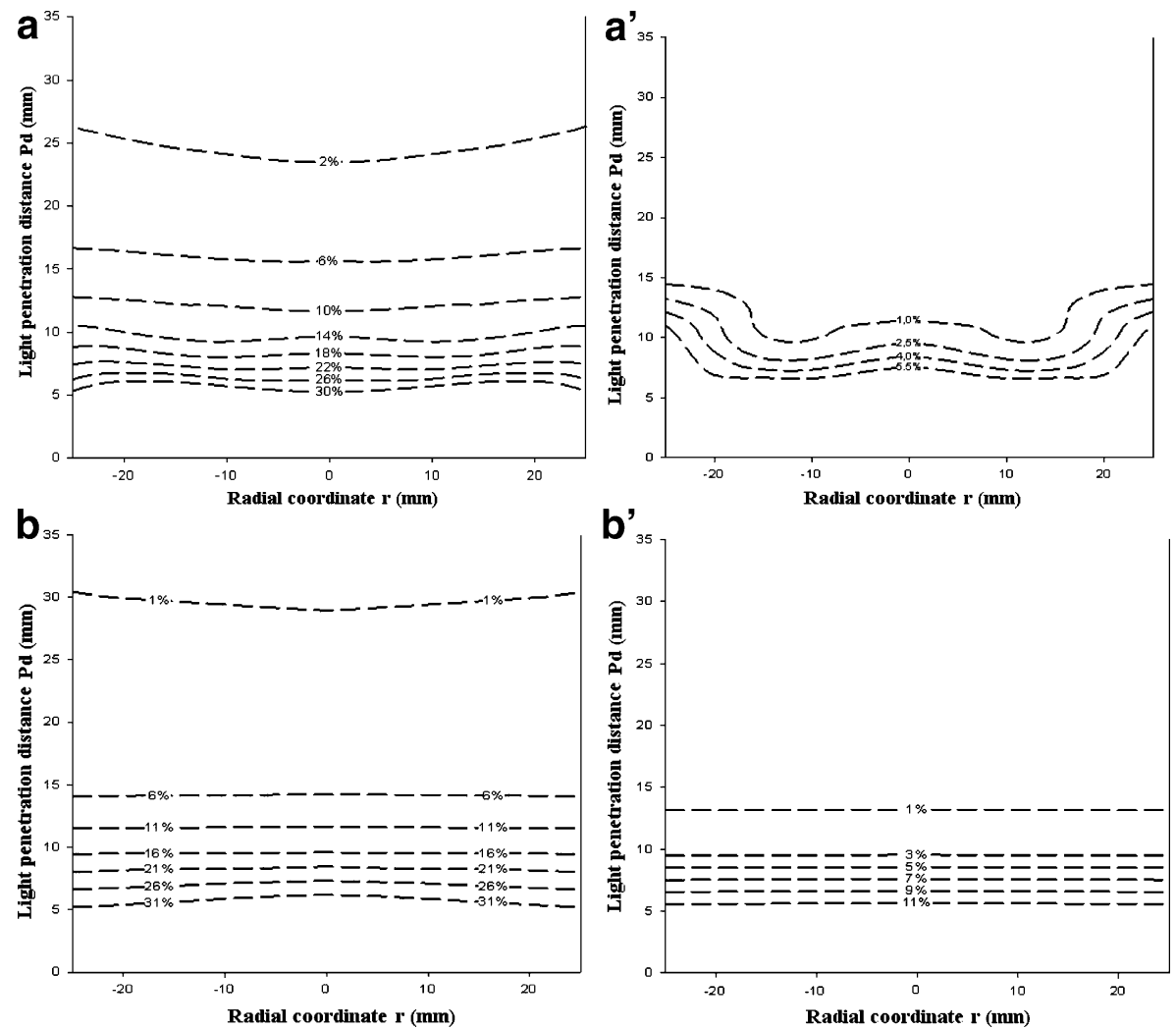

Fig. 2 Cross-sectional distribution of light intensity within the airlift downcomer filled with algal cell suspension as a function of the light penetration distance $(\mathrm{Pd})$ and radial coordinate $(r)$, where $r=0$ corresponds to the axis of the reactor, where $\mathbf{a ~ P B R}_{\mathrm{C}}$ with $0.95 \mathrm{~kg} \mathrm{~m}^{-3}, \mathbf{a}^{\prime} \mathrm{PBR}_{\mathrm{C}}$ with $2.67 \mathrm{~kg} \mathrm{~m}^{-3}, \mathbf{b} \mathrm{PBR}_{\mathrm{P}}$ with $0.95 \mathrm{~kg} \mathrm{~m}^{-3}$, and $\mathbf{b}^{\prime} \mathrm{PBR}_{\mathrm{P}}$ with $2.76 \mathrm{~kg} \mathrm{~m}^{-3}$

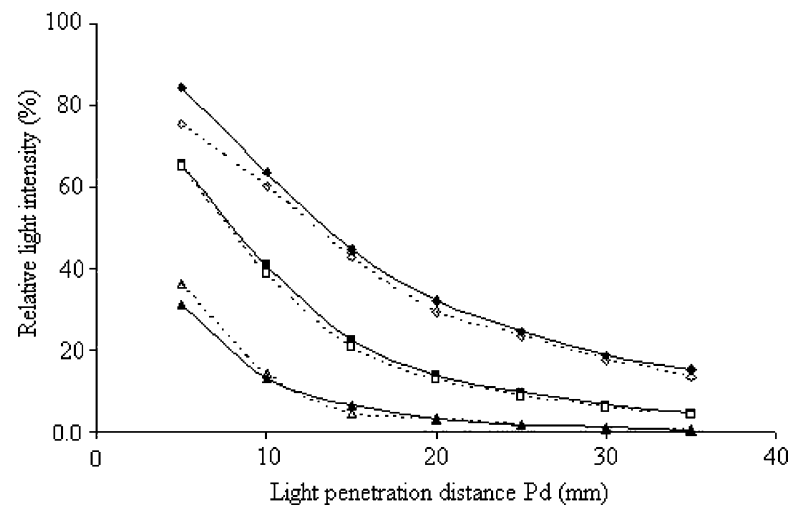

Fig. 3 Relative light intensity distribution (in percent) in the two airlift downcomer geometries (closed symbols circular geometry and open symbols plane geometry) filled with algal cell suspension (filled diamonds $0.35 \mathrm{~kg} \mathrm{~m}^{-3}$, filled squares $0.50 \mathrm{~kg} \mathrm{~m}^{-3}$, and filled triangles $0.95 \mathrm{~kg} \mathrm{~m}^{-3}$ ) as a function of the light penetration distance $(\mathrm{Pd})$. These data points correspond to measurements made for $r=0 \mathrm{~mm}$ 
small differences might be attributed, mainly, to the light incidence angle at the reactor surface. However, for higher cell concentrations (Fig. 2a', b'), the effect of the geometry becomes more evident, and a clear difference can be observed in the RLI that reaches zones of the reactor with the same light penetration distance $(\mathrm{Pd})$ but with different axial coordinates $(r)$. The fact that this difference is almost inexistent for the points at $r=0$ and increases for increasing values of $|r|$ is a clear indication that the influence of the curved surface of the circular reactor in the availability of the light inside the vessel is a positive one, when compared to the plane geometry. Such differences are the result of both the effect of the curved surface of the circular reactor and of the higher intensity of the scattering phenomena due to the higher concentration of cells present in the reactor. For the squared geometry, all the points at a given distance from the light source will have the same light penetration distance (independently of their radial coordinate) and therefore, will be essentially under the same RLI (Fig. 2b'). On the contrary, for the circular geometry, to the same distance from the light source, there will be different light penetration distances depending on the radial coordinate; this will have obvious consequences on the value of RLI (Fig. 2a') once the points at the same distance from the light source will have improved RLI values for increasing values of the modulus of the radial coordinate.

As mentioned before, this effect is much more evident at higher cell concentrations due to the light scattering effects provoked by the cells: In a limiting case, if no cells are present and if no light refraction occurs at the acrylic reactor wall, virtually no differences would be observed between the two geometries (Fig. 2a, b).

Figure 3 shows the attenuation of the light intensity as a function of the penetration distance for different microalgae concentrations and for the two reactor geometries under consideration, along the central radial coordinate $(r=0)$. These results confirm the analysis made from the data of Fig. 2, but they also allow establishing correlations Eq. 2 and Table 1 between the RLI and the penetration distance $(\mathrm{Pd})$ for both geometries.

$$
\mathrm{RLI}=y_{0}+(a / \mathrm{Pd})+\left(b / \mathrm{Pd}^{2}\right)+\left(c / \mathrm{Pd}^{3}\right)
$$

where $\mathrm{RLI}$ is in $\%, \mathrm{Pd}$ is in $\mathrm{mm}$, and $y_{0}, a, b$, and $c$ are the regression coefficients, the values of which are presented in Table 1 . This equation is a third order inverted polynomial, which was chosen among six other possible models available in SigmaPlot (trial version, Systat software, Inc; Germany). These correlations will be useful when establishing the final design of the airlift bioreactor and, later on, during scaling up procedures.

It is generally accepted that a culture can be considered under darkness conditions when the light intensity is below a certain limit (between 0 and $15 \mu \mathrm{E} \mathrm{m}^{-2} \mathrm{~s}^{-1}$, according to Suh

Table 1 Coefficients from Eq. 2 for the circular and plane geometries and for different microalgae cell concentrations with the respective value of $R^{2}$.

\begin{tabular}{lcccccc}
\hline PBR & Cell concentration $\left(\mathrm{kg} \mathrm{m}^{-3}\right)$ & \multicolumn{2}{l}{ Coefficient $\left(\times 10^{-2}\right)$} & \multirow{2}{*}{$R^{2}$} \\
\cline { 3 - 6 } & & \multicolumn{1}{l}{$y_{0}$} & $a$ & $b$ & $c$ & \\
\hline Circular & 0.35 & -0.1147 & 9.9044 & -22.023 & -17.7474 & 0.999 \\
& 0.50 & -0.0221 & 1.0641 & 53.426 & -209.136 & 0.999 \\
& 0.95 & -0.0154 & 0.01973 & 18.3721 & -56.1530 & 0.999 \\
\multirow{2}{*}{ Plane } & 0.35 & -0.1284 & 9.9721 & -25.1507 & -13.2912 & 0.999 \\
& 0.50 & -0.0207 & 0.9085 & 50.9146 & -193.400 & 1.00 \\
& 0.95 & 0.0356 & -2.1538 & 44.9657 & -130.148 & 0.999 \\
\hline
\end{tabular}


and Lee [18]; in the present work, an intermediate value of $7.0 \mu \mathrm{E} \mathrm{m}^{-2} \mathrm{~s}^{-1}$ was used, which corresponds to $10 \%$ of the light intensity used as reference). The volume fraction of the reactor above the limit of darkness was, thus, calculated based on the axial relative light intensity distribution represented in Fig. 2. This volume fraction was calculated for both reactor geometries and is compared in Fig. 4.

For instance, at a cell concentration of $0.5 \mathrm{~kg} \mathrm{~m}^{-3}$, the volume which receives a light intensity above $7.0 \mu \mathrm{E} \mathrm{m}^{-2} \mathrm{~s}^{-1}$ corresponds to $94 \%$ and $71 \%$ of the total volume of the $\mathrm{PBR}_{\mathrm{C}}$ and $\mathrm{PBR}_{\mathrm{P}}$, respectively, while those values are reduced to $43 \%$ and $23 \%$, respectively, at a cell concentration of $1.5 \mathrm{~kg} \mathrm{~m}^{-3}$. The results in Fig. 4, thus, show that the circular geometry allows a better light penetration for similar microalgae cell concentrations than the plane geometry, which means that a higher volume fraction of the reactor will be receiving sufficient amounts of light to avoid darkness conditions. Based on Fig. 4 and considering all the other constant variables, the volumetric productivity is expected to be higher in a PBR with a circular geometry.

\section{Qualitative Characterization of Light}

Microalgal pigments change with algal variety, and therefore, the influences of different light qualities upon the physiological properties of different algae, such as growth, photosynthesis, and cellular metabolism, are diverse. Figure 5 shows the changes in the quality of the light reaching different depths inside the PBR. The depletion of light at certain wavelengths is obvious and, e.g., for a cell concentration of $0.95 \mathrm{~kg} \mathrm{~m}^{-3}$, almost all the radiation in the range of $400-450$ and $650-680 \mathrm{~nm}$ is absorbed/scattered in the first $5 \mathrm{~mm}$ of cell suspension.

The attenuation of light was higher for the blue $(400-500 \mathrm{~nm})$ and red $(650-700 \mathrm{~nm})$ regions of the spectrum than for the green region $(500-650 \mathrm{~nm})$, which was more obvious at a higher cell concentration. This is because blue and red lights are mostly consumed by the microalgae, while the green light could penetrate further into the algal suspension [19].

These results are due to the fact that the main pigments present in the cells of $C$. vulgaris (carotenoids and chlorophylls) absorb preferentially in the "blue" region and in the "red" region in the case of chlorophyll. C. vulgaris is known to be deficient in pigments absorbing light around $550 \mathrm{~nm}$ (green light) [20].

Apparently, only when preferred wavelengths are "consumed" will the system start to use other less-preferred wavelengths. This hypothesis is supported by Fig. 6 where

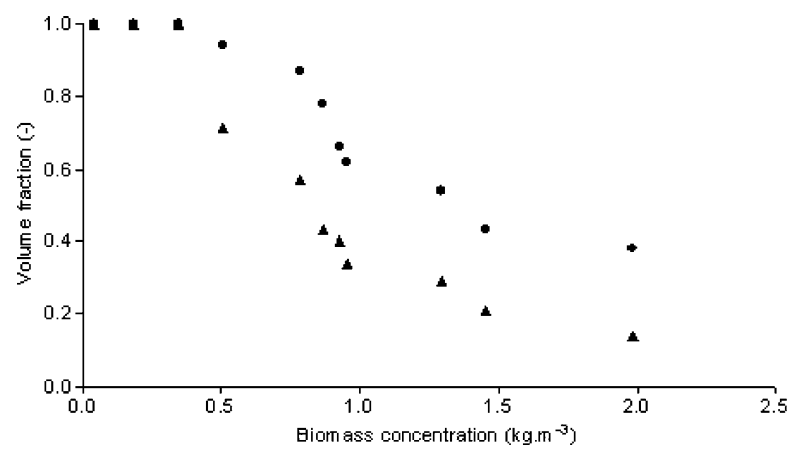

Fig. 4 Volume fraction of the PBR (referred to the total culture volume) where the RLI is higher than $10 \%$ of the reference intensity $\left(70 \mu \mathrm{E} \mathrm{m}^{-2} \mathrm{~s}^{-1}\right)$; circles $\mathrm{PBR}_{\mathrm{C}}$, triangles $\mathrm{PBR}_{\mathrm{P}}$ 


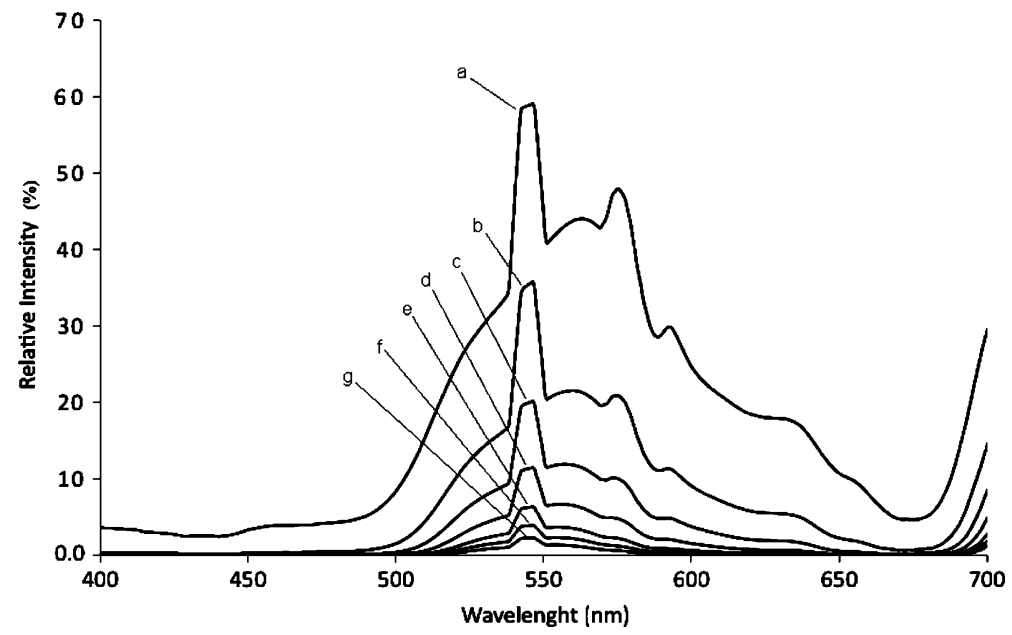

Fig. 5 Relative light intensity spectra for different light penetration distances within the $\mathrm{PBR}_{\mathrm{C}}(\mathrm{cell}$ concentration $=0.95 \mathrm{~kg} \mathrm{~m}^{-3}$ ); a $5 \mathrm{~mm}, b 10 \mathrm{~mm}, c 15 \mathrm{~mm}, d 20 \mathrm{~mm}$, e $25 \mathrm{~mm}, f 30 \mathrm{~mm}$, and $\mathrm{g} 35 \mathrm{~mm}$

it is shown that while the relative intensity in the blue and red regions is still considerable (above 20\%), the less-preferred wavelengths remain with very high intensities (close to 100\%). However, when the blue and red regions are almost totally absorbed, the system seems to effectively start absorbing in the green region of the spectrum.

Regardless of the wavelength of the light, the RLI declined with increasing cell concentration and eventually, reached zero when the cell concentration was higher [19]. Since photons are particles, the light is not only absorbed but also scattered randomly in the medium. Light scattering, thus, justifies that despite not being absorbed by the microalgae cells, green light was considerably attenuated in the algal suspension.

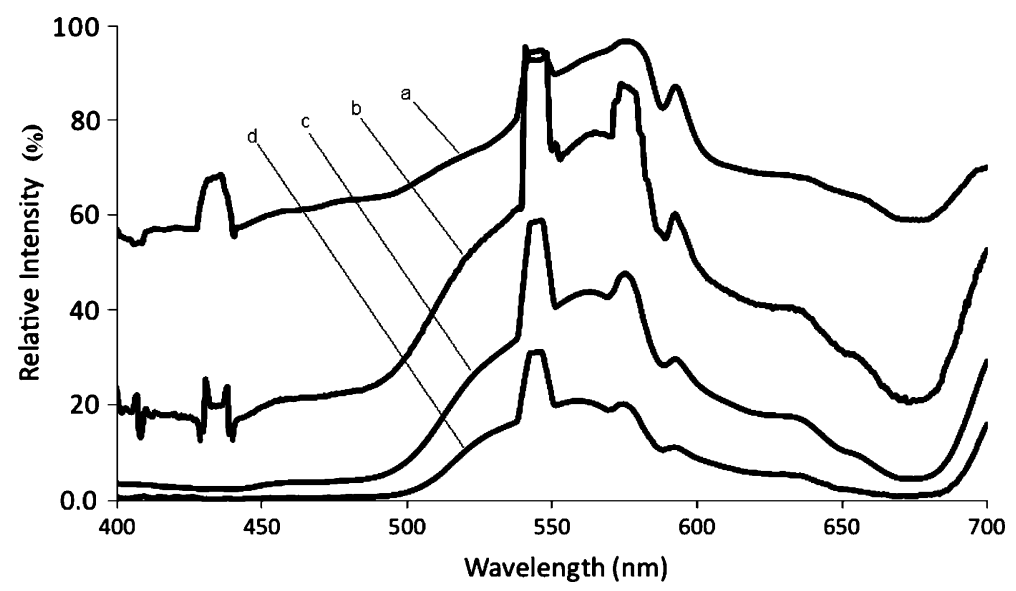

Fig. 6 Relative light intensity spectra for different cell concentrations within $\mathrm{PBR}_{\mathrm{C}}$ (light penetration distance $=5 \mathrm{~mm}$ ); $a 0.18 \mathrm{~kg} \mathrm{~m}^{-3}, b 0.50 \mathrm{~kg} \mathrm{~m}^{-3}, c 0.95 \mathrm{~kg} \mathrm{~m}^{-3}$, and $d 1.99 \mathrm{~kg} \mathrm{~m}^{-3}$ 


\section{Conclusions}

Optical fiber technology was used as a new methodology for the characterization of light regime in a PBR, thus, allowing the quantitative and qualitative characterization of light in two different geometries of the downcomer of an airlift PBR. It was concluded that when compared with the plane geometry, the circular geometry allows a more efficient light penetration and a higher fraction of illuminated volume inside the PBR. It was shown that the attenuation of light intensity is dependent on its wavelength, cell concentration, geometry of PBR, and the penetration distance of light.

An equation to correlate the RLI with the penetration distance $(\mathrm{Pd})$ for both geometries, and different microalgae cell concentrations is now available. These results and methodologies presented here will be determinant to improve the design of the existing airlift PBR toward a more efficient utilization of light energy with expected improvements of biomass yield and starch productivity.

Acknowledgments This work was supported by the Fundação para a Ciência e a Tecnologia through B. Fernandes grant SFRH/BD/44724/2008 and G. Dragone grant SFRH/BPD/44935/2008.

\section{References}

1. Gordon, J. M., \& Polle, J. E. W. (2007). Applied Microbiology and Biotechnology, 76, 969-975.

2. Benemann, J. R., Tillett, D. M., \& Weissman, J. C. (1987). Trends in Biotechnology, 5, 47-53.

3. Morita, M., Watanabe, Y., \& Saiki, H. (2001). Biotechnology and Bioengineering, 74(6), 476-475.

4. Csogör, Z., Herrenbauer, M., Schmidt, K., \& Posten, C. (2001). Journal of Applied Phycology, 13, 325333.

5. Merchuk, J. C., Garcia-Camacho, F., \& Molina-Grima, E. (2007). Chemical and Biochemical Engineering Q, 21(4), 345-355.

6. Rabe, A. E., \& Benoit, A. (1962). Biotechnology and Bioengineering, 4, 337-390.

7. Frohlich, B. T., Webster, I. A., Ataai, M. M., \& Shuler, M. L. (1983). Biotechnology and Bioengineering Symposium, 13, 331-350.

8. Erickson, L. E., \& Lee, H. Y. (1986). Algal biomass technologies. In W. Barclay \& R. P. McIntosh (Eds.), An interdisciplinary perspective (p. 197). Berlin: Nova Hedwigia.

9. Grima, E. M., Fernández, F. G. A., Camacho, F. G., \& Chisti, Y. (1999). Journal of Biotechnology, 70, 231-247.

10. Wu, X., \& Merchuk, J. C. (2004). Chemical Engineering Science, 59, 2899-2912.

11. Cornet, J. F., Dussap, C. G., \& Gros, J. B. (1998). Advances in Biochemical Engineering/Biotechnology, 59, 155-224.

12. Pruvost, J., Pottier, L., \& Legrand, J. (2006). Chemical Engineering Science, 61, 4476-4489.

13. Douskova, I., Doucha, J., Machat, J., Novak, P., Umysova, D., Vitova, M., \& Zachleder V (2008) Proceedings of the International Conference: Bioenergy: Challenges and Opportunities, 6th/9th April 2008, Guimarães, Portugal

14. Ranjbar, R., Inoue, R., Katsuda, T., Yamaji, H., \& Katoh, S. (2008). Journal of Bioscience and Bioengineering, 106(2), 204-207.

15. Jacob-Lopes, E., Scoparo, C. H. G., Lacerda, L. M. C. F., \& Franco, T. T. (2009). Chemical Engineering and Processing, 48(1), 306-310.

16. Laws, E. A. (1980). Limnology and Oceanography, 25, 455-473.

17. Ree, G. Y., \& Gotham, I. J. (1981). Limnology and Oceanography, 26, 649-659.

18. Suh, I. S., \& Lee, S. B. (2003). Biotechnology and Bioengineering, 82, 2.

19. Yun, Y.-S., \& Park, J. M. (2001). Applied Microbiology and Biotechnology, 55, 765-770.

20. Janssen, M., Tramper, J., Mur, L. R., \& Wijffels, R. H. (2003). Biotechnology and Bioengineering, 81(2), $193-210$. 